\title{
FONTES DE ADUBAÇÃO ORGÂNICA E NÍVEIS SALINOS NO CRESCIMENTO INICIAL DE MARACUJAZEIRO
}

\author{
Joseano Graciliano da Silva ${ }^{1}$, Giuliana Naiara Sales Barros ${ }^{2}$, Reginaldo Gomes Nobre \\ ${ }^{1}$ Universidade Federal de Pelotas - UFPEL, RS. ${ }^{2}$ Universidade Federal de Campina Grande, Campina Grande, PB. E-mail: \\ joseano_agronomo@outlook.com
}

\section{RESUMO}

O maracujazeiro é uma das frutíferas que mais vem ganhando destaque no setor frutícola por ser bastante utilizado na alimentação, na indústria farmacológica e na ornamentação. Seu cultivo na região Nordeste do Brasil apresenta algumas limitações devido ao teor de matéria orgânica do solo e/ou ao uso de água de elevada salinidade em algumas propriedades. Diante disso, objetivou-se avaliar o efeito de diferentes tipos de esterco e a interação com diferentes níveis salinos da água de irrigação. $O$ delineamento estatístico adotado foi o de blocos casualizados, com esquema fatorial $3 \times 5$, sendo três tipos de esterco (bovino, caprino e de aves) e cinco níveis salinos $\left(0,3 ; 1,3 ; 2,3 ; 3,3 ; 4,3 \mathrm{dS} \mathrm{m}^{-1}\right)$ com quatro repetições e uma planta por repetição. Os dados foram analisados através do programa estatístico Sisvar 5.3. Concluiu-se que não houve interação entre os tipos de esterco e os níveis salinos, contudo, o esterco caprino favoreceu o crescimento das mudas de maracujazeiro amarelo. Por outro lado, o aumento nos níveis salinos em até 4,3 $\mathrm{dS} \mathrm{m}^{-1}$ prejudicou o crescimento de todas as variáveis até os 60 DAS.

Palavras-chave: esterco; Passiflora edulis; salinidade; substrato.

\section{SOURCES OF ORGANIC FERTILIZATION AND SALINE LEVELS IN THE INITIAL GROWTH OF YELLOW PASSION FRUTI}

\begin{abstract}
The passion fruit is one of the fruit that has been gaining more prominence in the fruit sector because it is widely used in food, pharmacology and ornamentation. Its cultivation in the northeastern region of Brazil presents some limitations due to the organic matter content of the soil and / or the use of water of high salinity in some properties. The objective of this study was to evaluate the effect of different types of manure and the interaction with different saline levels of irrigation water. The statistical design adopted was a randomized complete block design with $3 \times 5$ factorial design, with three types of manure (bovine, goat and poultry) and five saline levels $\left(0.3,1.3,2.3,3.3 ; 4.3 \mathrm{dS} \mathrm{m}^{-1}\right.$ ) with four replicates and one plant per replicate. The data were analyzed using the statistical program Sisvar 5.3. It was concluded that there was no interaction between manure types and saline levels, however, goat manure favored the growth of yellow passion fruit seedlings. On the other hand, the increase in saline levels up to $4.3 \mathrm{dS} \mathrm{m}^{-1}$ impaired the growth of all variables up to 60 DAS.
\end{abstract}

Keyword: manure; Passiflora edulis; salinity; substrate.

\section{INTRODUÇÃO}

O maracujazeiro é uma frutífera, com espécies tropicais e subtropicais, algumas nativas do Brasil. Embora se tenha grande variabilidade, os cultivos comerciais baseiam-se na cultivar Passiflora edulis f. flavicarpa responsável por 95\% dos pomares, em função do vigor dos frutos, produtividade e sabor do suco, sendo esta variedade conhecida popularmente como maracujá-amarelo ou azedo (SANTOS et al., 2016).

O Brasil se destaca como o maior produtor e consumidor mundial da fruta, abrangendo em torno de 61 mil hectares de área colhida com produção superior a 694539 toneladas por ano (JESUS et al., 2018), salientando-se as regiões Norte e Nordeste, com mais de $60 \%$ da produção em função das suas condições edafoclimáticas favoráveis para 
exploração da cultura, com exclusão da pluviosidade (CAVALCANTE et al., 2006). Levando em consideração a região Nordeste, como a de mais significância para a produção do maracujazeiro amarelo, os problemas de sais no solo e nos mananciais em muitas áreas têm comprometido severamente a formação de mudas e o estabelecimento da cultura sob manejo convencional. Este cenário é mais evidente em perímetros irrigados, devido ao manejo ainda pouco eficiente da irrigação, associado aos problemas de drenagem do solo.

Inclusivamente, a qualidade da água de irrigação nas principais áreas produtoras de maracujá, nos estados da Paraíba e do Rio Grande do Norte, é, na maioria, proveniente de poços e açudes que apresentam condutividade elétrica superior a $1,5 \mathrm{dS} \mathrm{m}^{-1}$ (AYERS; WESTCOT, 1999). Esta situação pode comprometer o crescimento, floração, número e peso médio do fruto, redução do ciclo do maracujazeiro e, por conseguinte, provocar redução da produtividade (CAVALCANTE et al., 2006).

O maracujazeiro, conforme Ayers e Westcot (1999) é uma cultura de elevada sensibilidade à ação dos sais, devido aos efeitos negativos na germinação e na formação inicial durante a produção das mudas, inibindo o crescimento e o estabelecimento da cultura no campo. Diante dessa situação, se faz necessária a adoção de técnicas que reduzam os efeitos negativos da salinidade durante o crescimento inicial do maracujazeiro amarelo, de modo a diminuir a heterogeneidade no crescimento e formação das mudas (CAVALCANTE et al., 2007a; 2007b).

Superadas as limitações, a produção de mudas torna-se fundamental para o bom estabelecimento do estande em condições de campo. Sá et al. (2014) e Medeiros et al. (2016) destacam a importância de se utilizar adubos orgânicos como esterco de aves e caprino para melhorar a estrutura dos solos e o crescimento radicular das culturas, levando em consideração as propriedades físico-químicas do adubo.

Diante disso, objetivou-se avaliar a influência de diferentes fontes de matéria orgânica na produção de mudas de maracujazeiro amarelo submetidos a distintos níveis de salinidade da água de irrigação.

\section{MATERIAL E MÉTODOS}

O experimento foi desenvolvido em ambiente protegido, no Centro de Ciências e
Tecnologia Agroalimentar da Universidade Federal de Campina Grande, Campus Pombal-PB. Localizado geograficamente a $06^{\circ} 46^{\prime} 13^{\prime \prime} \mathrm{S}$ e $37^{\circ}$ 48' 06" W, com altitude de 184 metros. O clima do município, segundo a classificação de Koopen, é do tipo $A w^{\prime}$, que representa clima quente e úmido com chuvas de verão/outono, com precipitação média de $800 \mathrm{~mm}^{2} \mathrm{ano}^{-1}$.

0 delineamento experimental foi realizado em blocos casualizados com esquema fatorial $3 \times 5$, sendo três fontes de matéria orgânica (esterco bovino, caprino e de aves) e cinco níveis salinos $(0,3 ; 1,3 ; 2,3 ; 3,3$; e $4,3 \mathrm{dS} \mathrm{m}$ ${ }^{1}$ ), com 4 repetições, totalizando 60 unidades experimentais. $\mathrm{O}$ fator salinidade foi baseado na salinidade limiar da cultura, a qual situa-se na faixa de 2,3 dS $\mathrm{m}^{-1}$ (FREIRE et al., 2011). As variáveis emergência e índice de velocidade de emergência, bem como as variáveis altura, diâmetro e número de folhas aos 30 DAS foram submetidas a análise de variância com médias comparadas pelo teste de Tukey a $5 \%$ de probabilidade, com auxílio do programa estatístico Sisvar 5.3 (FERREIRA, 2011).

As sementes utilizadas neste experimento foram provenientes de frutos completamente maduros, comercializados no mercado público da cidade de Pombal - PB. As sementes foram extraídas dos frutos cortando-os ao meio e, então, extraídas as sementes. $\mathrm{O}$ arilo foi removido mecanicamente com auxílio de um liquidificador acionando o botão pulsar por 50 vezes, cujas hélices estiveram envoltas com fita crepe e usando $200 \mathrm{ml}$ de semente com arilo mais $300 \mathrm{ml}$ de água (SILVA et al., 2013). Posteriormente, as sementes foram postas para secar a sombra sobre folhas de papel toalha durante sete dias em condições ambiente e armazenadas para uso posterior.

O semeio foi realizado em sacolas de polietileno, com capacidade para $0,5 \mathrm{dm}^{3}$, preenchidas com solo do tipo Neossolo flúvico, areia e esterco nas proporções 2:1:1, respectivamente. As irrigações foram realizadas duas vezes ao dia, usando água de boa qualidade $\left(0,3 \mathrm{dS} \mathrm{m}^{-1}\right)$ com auxílio de regador até os 30 dias após a semeadura (DAS), visando a manutenção da umidade no substrato com valores próximos da capacidade de campo.

O preparo das águas com distintos níveis salinos para uso na irrigação foram obtidas pela adição de cloreto de sódio em água proveniente do sistema de abastecimento local, cuja quantidade $(\mathrm{Q})$ foi determinada pela equação de 
Rhoades et al. (2000), sendo $Q(m g ~ L-1)=C E a x$ 640 , em que CEa (dS $\mathrm{m}^{-1}$ ) representa o valor desejado da condutividade elétrica da água, calibradas com auxílio de um condutivímetro portátil e acondicionadas em recipientes plásticos $(100$ L) fechados. As irrigações com água salinizada compreenderam o período de 30 a 60 DAS, aplicando-se um volume tal que proporcionasse um dreno menor ou igual a $10 \%$ do volume aplicado diariamente.

As contagens de emergência e índice de velocidade de emergência foram realizadas dos sete aos 30 DAS (BRASIL, 2009; WAGNER JÚNIOR et al. (2011). Os dados foram calculados de acordo com a fórmula proposta por Maguire (1962). As avaliações de crescimento foram realizadas aos 30, 45 e 60 DAS, determinando-se as seguintes variáveis:

- Altura das plantas: medindo-se do colo até o ápice caulinar da planta, com auxílio de régua graduada em centímetros;

- Comprimento da raiz: medindo-se do colo até o ápice radicular da planta, com auxílio de régua graduada em centímetros;

- Número de folhas: obtidos a partir da contagem das folhas completamente formadas; e

- Diâmetro do caule: obtido com auxílio de paquímetro digital, cujos valores foram expressos em milímetros).

Aos 60 DAS todas as plantas foram coletadas e pesadas em balança analítica para a quantificação da massa fresca das folhas, caule e da raiz. A partir de então, dividiu-se estes valores pelo número de plantas, obtendo assim, o peso por planta em cada tratamento. Para a determinação do peso de massa seca as plantas foram acondicionadas em sacos de papel do tipo Kraft e mantidas em estufa a $65 \% \mathrm{C}$, com circulação forçada de ar, até atingir peso constante (AGUIAR et al., 2014). Os valores obtidos foram expressos em g planta ${ }^{-1}$.

Os dados obtidos foram submetidos à análise de variância e, quando significativos, aplicou-se a análise de regressão para o fator salinidade, enquanto que as médias referentes ao fator esterco foram comparadas pelo teste Tukey ao nível de $5 \%$ de probabilidade, utilizando o programa estatístico Sisvar 5.3 (FERREIRA, 2011).

\section{RESULTADOS E DISCUSSÃO}

Na Tabela 1 é apresentado o resumo da análise de variância para os fatores isolados e da interação entre fonte de matéria orgânica e níveis salinos da água de irrigação. Foi observado efeito significativo $(p \leq 0,05)$ para os fatores isolados, contudo, não foi observada, interação significativa para os diferentes níveis salinos em função das fontes de matéria orgânica até os 60 DAS. 
Tabela 1. Resumo da análise de variância para as variáveis emergência (E\%), índice de velocidade de emergência (IVE), altura das plantas (ALT), diâmetro do caule (DC), número de folhas (NF), comprimento da raiz $(C R)$ e massa fresca e seca das folhas, caule e raiz (MFF, MFC, MFR, MSF, MSC, MSR) até os 60 DAS em mudas de maracujazeiro sob diferentes fontes de esterco e níveis salinos da água de irrigação.

\begin{tabular}{|c|c|c|c|c|c|c|c|c|}
\hline FV & DAS & $\begin{array}{l}\text { Esterco } \\
\text { (E) }\end{array}$ & $\begin{array}{l}\text { Salinidade } \\
\text { (S) }\end{array}$ & $E \times S$ & Bloco & Erro & Média & $\begin{array}{l}C V \\
\text { (\%) }\end{array}$ \\
\hline$E \%$ & 30 & $381,874^{\mathrm{ns}}$ & - & - & 181,720 & 557,932 & 60 & 39,48 \\
\hline$I V E$ & 30 & $0,987^{* *}$ & - & - & $0,064^{\mathrm{ns}}$ & 0,035 & 0,478 & 39,05 \\
\hline$A L T$ & 30 & $5,105^{\mathrm{ns}}$ & - & - & $1,826^{\mathrm{ns}}$ & 2,019 & 4,45 & 31,92 \\
\hline$D C$ & 30 & $0,346^{\mathrm{ns}}$ & - & - & $0,134^{\mathrm{ns}}$ & 0,109 & 1,46 & 22,52 \\
\hline$N F$ & 30 & $0,970^{\mathrm{ns}}$ & - & - & $2,282^{\mathrm{ns}}$ & 1,946 & 4,00 & 38,60 \\
\hline GL & - & 2 & - & - & 3 & 54 & - & - \\
\hline \multirow[b]{2}{*}{$A L T$} & 45 & $12,217^{*}$ & $29,269^{* *}$ & $1,677^{\mathrm{ns}}$ & $8,457^{\mathrm{ns}}$ & 2,949 & 7,729 & 22,22 \\
\hline & 60 & $35,627^{* *}$ & $103,702^{* *}$ & $10,145^{\mathrm{ns}}$ & $11,472^{\mathrm{ns}}$ & 4,586 & 11,859 & 18,06 \\
\hline \multirow{2}{*}{$D C$} & 45 & $0,422^{\mathrm{ns}}$ & $0,656^{\mathrm{ns}}$ & $0,396^{\mathrm{ns}}$ & $0,227^{\mathrm{ns}}$ & 0,391 & 1,981 & 31,54 \\
\hline & 60 & $0,585^{\mathrm{ns}}$ & $1,379^{\mathrm{ns}}$ & $0,034^{\mathrm{ns}}$ & $0,286^{\text {ns }}$ & 0,369 & 2,778 & 21,86 \\
\hline \multirow{2}{*}{$N F$} & 45 & $0,867^{\mathrm{ns}}$ & $5,392^{\mathrm{ns}}$ & $2,711^{\mathrm{ns}}$ & $2,867^{\mathrm{ns}}$ & 3,080 & 6,267 & 28,01 \\
\hline & 60 & $0,717^{\mathrm{ns}}$ & $7,267^{*}$ & $1,394^{\mathrm{ns}}$ & $4,592^{\mathrm{ns}}$ & 2,466 & 8,517 & 18,44 \\
\hline$C R$ & 60 & $166,258^{* *}$ & $271,467^{* *}$ & $2,272^{\mathrm{ns}}$ & $123,750^{* *}$ & 7,490 & 12,979 & 21,09 \\
\hline MFF & 60 & $31,541^{* *}$ & $25,304^{* *}$ & $2,679^{\text {ns }}$ & $8,234^{* *}$ & 2,103 & 4,328 & 33,51 \\
\hline MFC & 60 & $0,700^{*}$ & $1,586^{* *}$ & $0,186^{\mathrm{ns}}$ & $0,407^{*}$ & 0,165 & 1,147 & 35,41 \\
\hline MFR & 60 & $14,013^{* *}$ & $14,013^{* *}$ & $0,657^{\mathrm{ns}}$ & $9,627^{\mathrm{ns}}$ & 1,397 & 2,869 & 41,19 \\
\hline MSF & 60 & $0,502^{\mathrm{ns}}$ & $0,874^{* *}$ & $0,220^{\mathrm{ns}}$ & $0,277^{\mathrm{ns}}$ & 0,160 & 0,7706 & 51,88 \\
\hline MSC & 60 & $0,083^{* *}$ & $0,089^{* *}$ & $0,019^{\mathrm{ns}}$ & $0,035^{*}$ & 0,015 & 0,2648 & 46,32 \\
\hline MSR & 60 & $0,669^{* *}$ & $0,927^{* *}$ & $0,152^{\mathrm{ns}}$ & $0,240^{\mathrm{ns}}$ & 0,111 & 0,4990 & 66,76 \\
\hline
\end{tabular}

$\begin{array}{lllllll}\mathrm{GL} & - & 2 & 4 & 8 & 3 & 42\end{array}$

${ }^{* *}=$ significativo ao nível de $1 \%$ de probabilidade $(p \leq 0,01) ;{ }^{*}=$ significativo ao nível de $5 \%$ de probabilidade $(p \leq 0,05) ;$ ns $=$ não significativo $(p \geq 0,05)$

Os dados apresentados na Tabela 1 para as avaliações até os 30 DAS, com exceção do índice de velocidade de emergência, não apresentaram efeito significativo em função dos tratamentos estudados. De acordo com Prisco e Gomes-Filho (2010), o caule é uma das estruturas de fundamental importância no ato de transplantio, pois ele, juntamente com a raiz, servirá de sustentação às folhas e demais estruturas, até que a planta se ramifique no sistema de tutoramento.

No que se refere ao índice de velocidade de emergência (Tabela 2), o uso de esterco caprino e bovino na produção de mudas de $P$. edulis L. proporcionaram um período de tempo relativamente menor até a emergência das plântulas, favorecendo o crescimento em altura aos 45 e 60 DAS, no entanto, essa característica não foi observada quando se empregou o esterco de aves, provavelmente, devido a necessidade de "curtir" o referido esterco. Por este motivo, a condutividade elétrica do dreno (CEd) foi superior a $10 \mathrm{dS} \mathrm{m}^{-1}$ no ato de semeadura. Este, por sua vez, foi influenciado pela presença de excrementos de aves ainda presentes no esterco. 
Tabela 2. Valores médios para as variáveis de índice de velocidade de emergência (IVE), altura de plantas aos 45 e 60 DAS (ALT45 e ALT60, respectivamente), comprimento da raiz (CR) e massa fresca e seca das folhas, caule e raiz (MFF, MFC, MFR, MSC, MSR, respectivamente) de mudas de maracujazeiro sob diferentes fontes de matéria orgânica.

\begin{tabular}{cccccccccc}
\hline ESTERCO & IVE & ALT45 & ALT60 & CR & MFF & MFC & MFR & MSC & MSR \\
\hline BOVINO & $0,58 \mathrm{a}$ & $8,15 \mathrm{a}$ & $13,03 \mathrm{a}$ & $13,27 \mathrm{~b}$ & $4,21 \mathrm{~b}$ & $1,21 \mathrm{ab}$ & $2,62 \mathrm{~b}$ & $0,31 \mathrm{a}$ & $0,44 \mathrm{~b}$ \\
CAPRINO & $0,63 \mathrm{a}$ & $8,20 \mathrm{a}$ & $12,14 \mathrm{a}$ & $15,70 \mathrm{a}$ & $5,64 \mathrm{a}$ & $1,29 \mathrm{a}$ & $3,80 \mathrm{a}$ & $0,30 \mathrm{a}$ & $0,70 \mathrm{a}$ \\
AVES & $0,22 \mathrm{~b}$ & $6,83 \mathrm{~b}$ & $10,40 \mathrm{~b}$ & $9,96 \mathrm{c}$ & $3,14 \mathrm{~b}$ & $0,94 \mathrm{~b}$ & $2,18 \mathrm{~b}$ & $0,19 \mathrm{~b}$ & $0,35 \mathrm{~b}$ \\
\hline
\end{tabular}

*Letras iguais na coluna não diferem entre si, estatisticamente, pelo teste Tukey $(p \leq 0,05)$.

De acordo com Marcos Filho, Kikuti e Lima (2009), a determinação do vigor em sementes pode ser utilizado para identificar lotes com emergência de plântulas mais rápida em campo ou em estufa, minimizando assim as condições adversas que ocorrem durante a fase inicial e o estabelecimento das plantas. Portanto, - IVE se torna uma das ferramentas essenciais para se caracterizar o vigor de sementes de $P$. edulis L., de modo que, maiores valores de IVE podem ser obtidos em lotes mais vigorosos (MAGUIRE, 1962) e sugerem um tempo menor até a estabilização da emergência em sementes.

No que se refere à altura das plantas de maracujá (Tabela 2), foi observado valores com comportamento estatístico semelhante em ambos os períodos de avaliação, no qual o uso de esterco bovino e caprino promoveram, um incremento médio de 9,62\%, em relação às plantas que foram cultivadas com esterco de aves. Resultados semelhantes foram observados por Araújo et al. (2010), trabalhando com mamão (Carica papaya L.), no qual, constataram aumento da parte aérea em mudas cultivadas em substratos contendo até $35 \%$ de esterco caprino.

De acordo com a Tabela 2, o esterco caprino apresenta-se como fonte de matéria orgânica que melhor favoreceu o crescimento radicular do maracujazeiro até os 60 DAS, período em que as plantas devem apresentar de quatro a seis folhas definitivas, e a formação de algumas gavinhas, sendo consideradas, portanto, ideais para o transplantio, de acordo com Cezar et al. (2015).

O efeito proporcionado pelo esterco caprino pode estar atrelado a características físico-químicas do esterco ao promover uma maior aeração e, por essa razão, fermentar rapidamente (ARAÚJO et al., 2010; FREIRE et al., 2011), podendo ser aproveitados na agricultura, após um breve período de curtição em relação aos demais tipos de esterco aqui utilizados.

Os resultados aqui apresentados sugerem que 0 crescimento em altura em mudas de $P$. edulis L. pode ter sido estimulado pelo crescimento radicular, favorecendo também, o número de folhas, bem como as demais variáveis apresentadas na Tabela 2. Portanto, o uso de substratos com características físico-químicas que proporcionem boa aeração, retenção de água e nutrientes podem favorecer o crescimento inicial em plantas de $P$. edulis L. até os 60 DAS.

As folhas, cuja função principal é realizar fotossíntese e trocas gasosas, tiveram sua massa fresca significativamente influenciada $(p \leq 0,05)$ pela adição de esterco caprino e negativamente pelo esterco bovino e de aves (Tabela 2). Estes resultados podem ser atribuídos á mineralização rápida do esterco caprino em relação aos demais tipos de esterco (ARAÚJO et al., 2010), permitindo assim, um maior acúmulo de massa fresca da parte aérea e do sistema radicular.

Os efeitos benéficos do esterco caprino na produção de mudas também foram registrados por Sá et al. (2014) em P. edulis L cultivadas em ambiente protegido, no município de Catolé do Rocha - PB. Os referidos autores obtiveram plantas com características agronômicas superiores quando empregaram de 39 a $47 \%$ de esterco em substituição ao solo.

De semelhante modo, o acúmulo de massa fresca do caule e da raiz (Tabela 2) resultou em valores que confirmam o uso de esterco caprino como fonte de matéria orgânica ideal para o cultivo de maracujazeiro até os 60 DAS. Vale salientar, ainda, que o esterco bovino pode ser empregado como alternativa de uso, contudo, sem resultar em redução significativa no acúmulo de massa fresca do caule para estas variáveis. Este fato está associado à altura das plantas e ao número de folhas (Tabela 1 e 2), uma vez que o maior crescimento em altura sugere maior particionamento de fotoassimilados da parte aérea e crescimento secundário em dicotiledôneas (ARAÚJO et al., 2010; CEZAR et al., 2015).

O incremento de massa seca nas diversas partes da planta, observadas no presente estudo 
(Tabela 2), demonstram a eficácia do tipo de esterco em relação aos demais em estudo, favorecendo assim, estruturas como o caule e a raiz das plantas. Estas, por sua vez, apresentam considerável importância na absorção e translocação de nutrientes e água às folhas, proporcionando então, plantas mais vigorosas e aptas ao transplantio até os 60 DAS.

Contudo, de acordo com Oliveira et al. (2015) o acúmulo de massa seca em algumas culturas pode estar atribuído ao vigor das sementes, sugerindo que sementes vigorosas darão origem a plantas com melhor crescimento da parte aérea e maior acúmulo de massa seca, corroborando com os resultados observados por Sá et al. (2014) ao empregarem doses de esterco caprino em níveis de até $42,2 \%$ em substituição ao solo, observaram, em mudas de maracujazeiro, um acúmulo de massa seca da parte aérea de até $4,38 \mathrm{~g}_{\text {planta }}{ }^{-1}$.

De acordo com as equações apresentadas na Figura $1 \mathrm{~A}$ é possível observar que o aumento unitário dos níveis salinos na água de irrigação proporcionou decréscimos de $36,2 \%$ e $46,6 \%$ para a variável altura das plantas aos 45 e 60 DAS, respectivamente. Estes resultados podem ser atribuídos aos efeitos tóxicos que o estresse salino pode provocar nas plantas (DEINLEIN et al., 2014; MEDEIROS et al., 2016), ocasionando um desequilíbrio nutricional e fisiológico com influência direta na conversão de carbono assimilado pelas plantas e promovendo reduções no crescimento e no acúmulo de biomassa das culturas.

Figura 1. Altura das plantas aos 45 e 60 DAS e número de folhas aos 60 DAS em mudas de $P$. edulis em diferentes níveis salinos da água de irrigação.
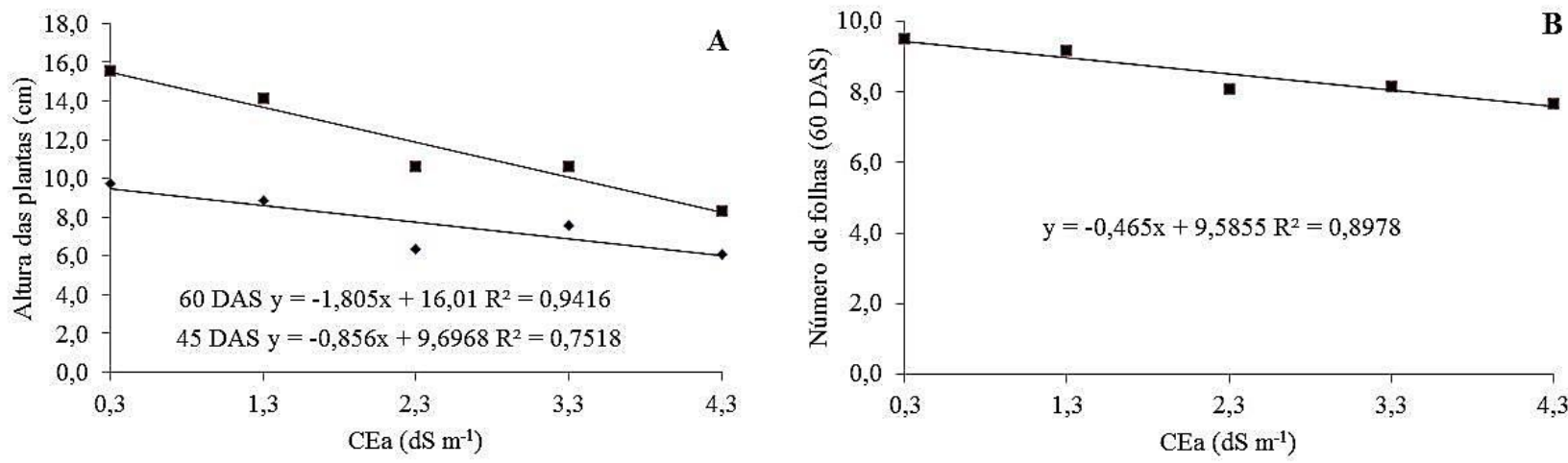

Fonte: Dados da Pesquisa

Os resultados observados neste trabalho para a variável altura das plantas (Figura 1A) são relativamente menores que os obtidos por Santos et al. (2016) ao avaliarem a emergência e o crescimento inicial de maracujazeiro cultivadas em substrato composto por solo argiloso, esterco de curral curtido e vermiculita, obtendo assim, plantas com até $10,80 \mathrm{~cm}$ de altura até os 60 DAS.

No que se refere ao número de folhas em plantas de $P$. edulis L. (Figura 1B), nota-se uma redução de $20,61 \%$ quando se empregou níveis salinos de até $4,3 \mathrm{dS} \mathrm{m}^{-1}$ até os 60 DAS, em relação às plantas que receberam água de menor CEa $\left(0,3 \mathrm{dS} \mathrm{m}^{-1}\right)$, sendo portanto, a variável de crescimento que apresentou menor redução até os 60 DAS. Esse efeito deletério causado pela salinidade da água de irrigação não foi observado em períodos anteriores nas avaliações de crescimento aos 30 e 45 DAS (Tabela 2).

Com relação às variáveis observadas na Figura 2A, constatou-se efeito linear decrescente, de modo que, o aumento unitário na salinidade da água de irrigação promoveu uma redução de 13,68 e de $13,48 \%$ nos valores de massa fresca das folhas e do caule, respectivamente, aos 60 DAS. De semelhante modo, a redução observada para as variáveis massa fresca da raiz e comprimento da raiz (Figura 2B) é da ordem de 13,61 e de $18,54 \%$, respectivamente. 
Figura 2. Massa fresca das folhas, caule e raiz (A), e da massa fresca da raiz (B) em plantas de $P$. edulis em diferentes níveis salinos da água de irrigação.

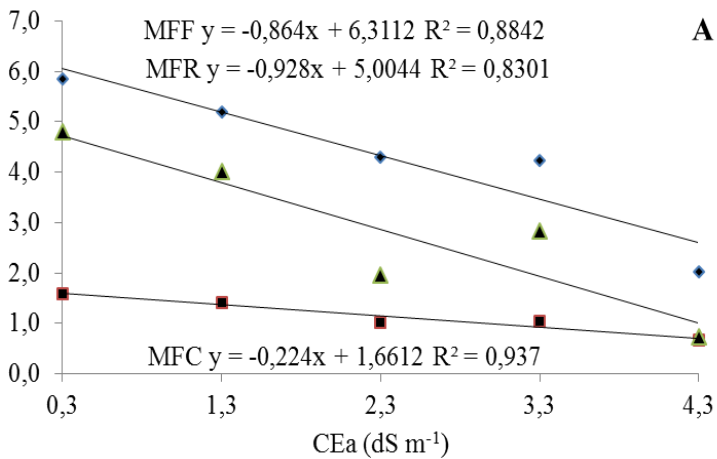

Fonte: Dados da Pesquisa

A redução da massa fresca nas plantas, observada na Figura 2A ocorreu, possivelmente, devido ao acúmulo de sais solúveis no substrato (CAVALCANTE et al., 2007a, MEDEIROS et al., 2016), dificultando assim, a absorção dos nutrientes pela raiz, culminando com a redução do número de folhas e, consequentemente, na atividade fotossintética da planta e no acúmulo de massa fresca e seca até os 60 DAS.

Na Figura 2A observa-se que o aumento nos níveis salinos prejudicou a massa fresca das raízes em até $78,54 \%$ de peso fresco, prejudicando a translocação de reservas para a parte aérea das plantas e o acúmulo de fotoassimilados, causando, então, prejuízos como redução nos teores de $\mathrm{N}$ translocado pelo floema da folha para as demais partes da planta (FREIRE et al., 2013; SANTOS et al., 2016).

De acordo com os valores observados para a variável comprimento da raiz (Figura 2B), a

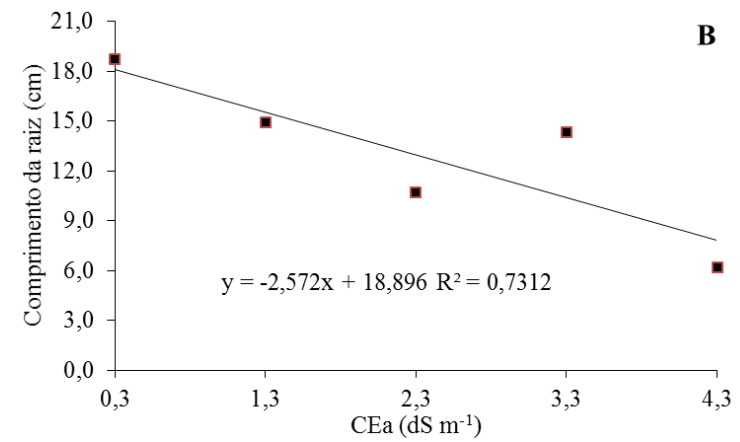

adição de sais na água de irrigação em níveis de até $4,3 \mathrm{dS} \mathrm{m}^{-1}$ promoveu a redução de $12,6 \mathrm{~cm}$, ou seja, $67,02 \%$ em relação as plantas irrigadas com água de $0,3 \mathrm{dS} \mathrm{m}^{-1}$, sendo, portanto, o parâmetro de crescimento mais afetado pela salinidade. Resultados semelhantes foram observados por Costa et al. (2005) em mudas de maracujazeiro amarelo irrigado com água de salinidade crescente, no qual se obteve redução de 8,2 a $10,4 \mathrm{~cm}$.

A redução de $50,29 \%$ na variável massa seca das folhas (Figura 3A) em plantas irrigadas com níveis salinos de até $4,3 \mathrm{dS} \mathrm{m}^{-1}$ em relação as plantas irrigadas com água de $0,3 \mathrm{dS} \mathrm{m}^{-1}$ pode ter sido causado pela inibição competitiva do $\mathrm{Na}^{+}$ pelo $\mathrm{Ca}^{2+}$ na micela do solo, bem como pelo acúmulo gradativo no vacúolo da célula a níveis tóxicos para a planta (DEINLEIN et al., 2014).

Figura 3. Massa seca das folhas (A) e do caule e raiz (B) em plantas de $P$. edulis em diferentes níveis salinos da água de irrigação.
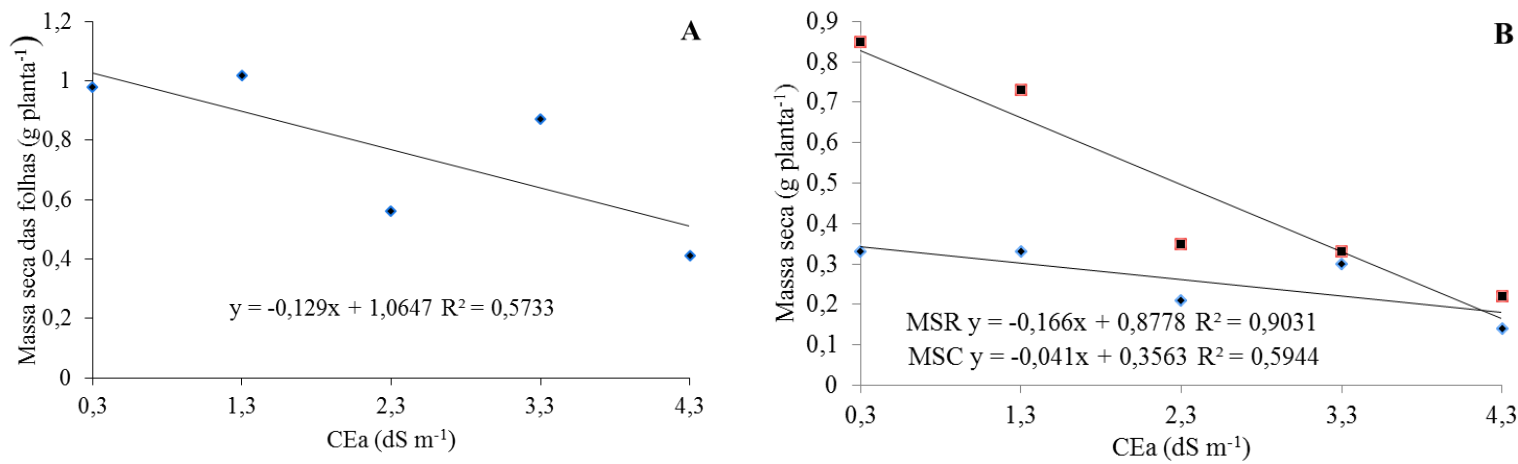

Fonte: Dados da Pesquisa 
Na Figura 3B é possível observar uma redução linear de 47,67 e de $80,19 \%$ para os valores de massa seca do caule e da raiz, respectivamente. A influência significativa da salinidade sobre estruturas de sustentação como as mencionadas, afetam o porte e a capacidade de sustentação da planta e o tempo necessário até o transplantio. De acordo com Zucareli et al. (2014), plantas menores ou nanicas tendem a priorizar determinadas estruturas que possam aumentar a taxa de sobrevivência da espécie ou apresentar efeitos negativos, a depender da espécie.

Como relatam Freire et al. (2013), a irrigação de diversas culturas com água de salinidade elevada, pode induzir modificações fisiológicas e comprometer o crescimento e o desenvolvimento das plantas. Outro agravante é a redução do potencial osmótico no solo devido ao $\mathrm{NaCl}$ (DEINLIN et al., 2014) presente na água usada na irrigação, o que limita o crescimento da folha e do caule, causando então a seca fisiológica, quando em condições extremas.

\section{CONCLUSÕES}

O emprego de esterco caprino como fonte de matéria orgânica no substrato usado para a produção de mudas de maracujazeiro amarelo favoreceu o crescimento das mudas até os 60 DAS para todas as variáveis analisadas. Todavia, o emprego do esterco de aves se mostrou ineficiente e não deve ser recomendado para a formação do dossel em $P$. edulis $\mathrm{L}$.

Plantas de maracujazeiro não apresentaram tolerância à salinidade da água de irrigação em níveis de até $4,3 \mathrm{dS} \mathrm{\textrm {m } ^ { - 1 }}$ e apresentaram decréscimo para a maioria das variáveis.

\section{REFERÊNCIAS BIBLIOGRÁFICAS}

AGUIAR, R.S., YAMAMOTO, L.Y., PRETI, E.A., SOUZA, G.R.B., SBRUSSI, C.A.G., OLIVEIRA, E.A.P., ASSIS, A.M., ROBERTO, S.R.; NEVES, C.S.V.J. Extração de mucilagem e substratos no desenvolvimento de plântulas de maracujazeiroamarelo. Semina: Ciências Agrárias, Londrina, v.35, n.2, p.605-612, 2014. http://doi.org/10.5433/1679-

0359.2014v35n2p605.

ARAÚJO, W.B.M.; ALENCAR, R.D.; MENDONÇA, V.; MEDEIROS, E.V.; ANDRADE, R.C.; ARAÚJO, R.R. Esterco caprino na composição de substratos para formação de mudas de mamoeiro. Ciência e Agrotecnologia, Lavras, v. 34, n.1, p.68-73,
2010.

AYERS, R.S.; WESTCOT, D.W. A qualidade da água na agricultura. Campina Grande: UFPB, 1999. (Estudos FAO: Irrigação e Drenagem, 29, Revisão)

BRASIL. Ministério da Agricultura, Pecuária e Abastecimento. Regras para análise de sementes. Brasília: Mapa/ACS, 2009.

CAVALCANTE, L.F.; ANDRADE, R.; COSTA, J.R.M.; CAVALCANTE, I.H.L.; GONDIM, S.C.; LIMA, E.M.; MACEDO, J.P.S.; SANTOS, J.B.; SANTOS, C.J.O. Maracujá-Amarelo e a Salinidade. In: CAVALCANTE, L.F.; LIMA, E.M. (org.). Algumas frutíferas tropicais e a salinidade. Jaboticabal: FUNEP, 2006. p. 91-115.

CAVALCANTE, L. F.; RODOLFO JÚNIOR, F.; SÁ; J. R.; CURVELO, C. R. S.; MESQUITA, E. F. Influência da água salina e matéria orgânica no desempenho do maracujazeiro amarelo e na salinidade do substrato. Irriga, Botucatu, v.12, n.4, p.505-518, 2007a. http://dx.doi.org/10.15809/irriga.2007v12n4p50 5-518.

CAVALCANTE, L.F.; SANTOS, G.D.; OLIVEIRA, F.A.; CAVALCANTE, I.H.L.; GONDIM, S.C.; CAVALCANTE, M.Z.B. Crescimento e produção do maracujazeiro amarelo em solo de baixa fertilidade tratado com biofertilizantes líquidos. Revista Brasileira de Ciências Agrárias, v.2, n.1, p.15-19, 2007b.

CEZAR, A.M.A.; SORGATO, J.C.; ROSA, D.N.C.J.; SOARES, J.S.; ROSA, Y.B.C.J. Aplicação foliar de $\mathrm{GA}_{3}$ no crescimento e desenvolvimento de Passiflora edulis Sims f. flavicarpa Degener. Revista Brasileira de Fruticultura, Jaboticabal, v.37, n.4, p.902-912, 2015. http://dx.doi.org/10.1590/0100-2945-233/14.

COSTA, E.G.; CARNEIRO, P.T.; SOARES, F.A.L.; FERNANDES, P.D.; GHEYI, H.R.; CAVALCANTE, L.F. Crescimento inicial do maracujazeiro amarelo sob diferentes tipos de níveis de salinidade da água de irrigação. Revista Brasileira de Engenharia Agrícola e Ambiental, Campina Grande, v.9, (supl.), p.242-247, 2005.

DEINLEIN, U.; STEPHAN, A.B.; HORIE, T.; LUO, W.; $\mathrm{XU}$, G.; SCHROEDER, J.L. Plant salt-tolerance mechanisms. Trends in Plant Science, v.19, n.6, p.371-379, 2014. http://dx.doi.org/10.1016/i.tplants.2014.02.001. 
FERREIRA, D. F. Sisvar - software: versão 5.3. Lavras: UFLA/DEX, Software. 2011.

FREIRE, J.L.O.; CAVALCANTE, L.F.; REBEQUI, A.M.; DIAS, T.J.; SOUTO, A.G.L. Necessidade hídrica do maracujazeiro amarelo cultivado sob estresse salino, biofertilização e cobertura do solo. Revista Caatinga, Mossoró, v.24, n.1, p.82-91, 2011.

FREIRE, J.L.O.; CAVALCANTE, L.F.; NASCIMENTO, R.; REBEQUI, A.M. Teores de clorofila e composição foliar do maracujazeiro irrigado com águas salinas e biofertilizante. Revista de Ciências Agrárias, Recife, v.36, n.1, p.57-70, 2013.

JESUS, C.A.S.; CARVALHO, E.V.; GIRARDI, E.A.; ROSA, R.C.C.; JESUS, O.N. Fruit quality and production of yellow and sweet passion fruit in Northern state of São Paulo. Revista Brasileira de Fruticultura, Jaboticabal, v.40, n.2, p.1-7, 2018. http://dx.doi.org/10.1590/0100-29452018968

MAGUIRE, J.D. Speed of germination-aid selection and evaluation for seedling emergence and vigor. Crop Science, v.2, p.176-177, 1962.

MARCOS FILHO, J.; KIKUTI, A.L.P.; LIMA, L.B. Métodos para avaliação do vigor de sementes de soja, incluindo a análise computadorizada de imagens. Revista Brasileira de Sementes, Londrina, v.31. n.1, p.102-112, 2009. http://dx.doi.org/10.1590/S010131222009000100012.

MEDEIROS, S.A.S.; CAVALCANTE, L.F.; BEZERRA, M.A.F.; NASCIMENTO, J.A.M.; BEZERRA, F.T.C.; PRAZERES, S.S. Água salina e biofertilizantes de esterco bovino na formação e qualidade de mudas de maracujazeiro amarelo. Irriga, Botucatu, v.21, n.4, p.779-795, 2016. http://dx.doi.org/10.15809/irriga.2016v21n4p77 9-795.

PRISCO, J. T.; GOMES FILHO, E. Fisiologia e bioquímica do estresse salino em plantas. Manejo da salinidade na agricultura: estudos básicos e aplicados. Fortaleza: INCTSal. p. 143160. 2010.

RHOADES, J.D.; KANDIAH, A.M.; MARSHALI, A.M. Uso de águas salinas para produção agrícola. Campina Grande: Universidade Federal da Paraíba, 2000. (Estudos da FAO - Irrigação e Drenagem, 48). 2000.
SÁ, F.V.S.; BERTINO, A.M.P.; FERREIRA, N.M.; BERTINO, A.M.P.; SOARES, L.S.; MESQUITA, E.F. Formação de mudas de maracujazeiro amarelo com diferentes doses de esterco caprino e volumes do substrato. Magistra, Cruz das Almas, v.26, n.4, p.482-492, 2014.

SANTOS, C.H.B.; CRUZ NETO, A.J.; JUNGHANS, T.G.; JESUS, O.N.; GIRARDI, E.A. Efeito de maturação de frutos e influência de ácido giberélico na emergência e crescimento de Passiflora spp. Revista Ciência Agronômica, Fortaleza, v.47, n.3, p.481-490, 2016.

SILVA, J.G.; LOPES, K.P.; CAVALCANTE, J.A.; SOUZA, T.M.A. Qualidade fisiológica de sementes de maracujazeiro submetido a diferentes métodos de remoção do arilo. In: CONGRESSO BRASILEIRO DE SEMENTES, 28. Anais [...] Florianópolis - SC: ABRATES. 1 p. CD-ROM. 2013.

SOUZA, E.J.; MAGALHÃES, F.F.; ALVES, C.Z.; CÂNDIDO, A.C.S.; SILVA, T.R.; CUNHA, F.F. Inoculação de Azospirillum brasiliense na qualidade fisiológica de sementes de milho doce. Nucleus, Ituverava, v.11, n.1, p.131-140, 2014. http://dx.doi.org/10.3738/1982.2278.939.

WAGNER JÚNIOR, A., SANTOS, C.E.M., SILVA, J.O.C., PIMENTEL, L.D.; BRCKNER, C.H.; MAZARO, S.M. Densidade de sementes de três espécies de maracujazeiro na emergência e desenvolvimento inicial das plântulas. Revista Brasileira de Agrociência, v.17, n.3-4, p.359-364, 2011. http://dx.doi.org/10.18539/cast.v17i3.2069.

ZUCARELI, V.; ONO, E.O.; BOARO, C.S.F.; BRAMBILLA, W.P. Desenvolvimento inicial de maracujazeiros (Passiflora edulis f. flavicarpa, $P$. edulis f. edulis e $P$. alata) enxertados sobre Passiflora cincinnata. Semina: Ciências Agrárias, Londrina, v.35, n.5, p.2325-2340, 2014. http://dx.doi.org/10.5433/1679-

0359.2014v35n5p2325.

Recebido para publicação em 20/06/2018

Revisado em 08/01/2019

Aceito em 08/01/2019 